\title{
The relationship between enzyme activity and neuroglia in plaques of multiple sclerosis
}

\author{
M. Z. M. IBRAHIM AND C. W. M. ADAMS \\ From the Department of Pathology, Guy's Hospital Medical School, London
}

Since Dawson's (1916) pathological studies on multiple sclerosis little further information has been obtained about the nature of the neuroglial reaction in the plaques of this disease and it is not known whether this response is primary or a secondary event in the process of demyelination. It has been suggested by Lumsden (Lumsden, 1951; McAlpine, Compston, and Lumsden, 1955) that the oligodendrocyte is selectively damaged in multiple sclerosis. 'A complete loss of this cell' was observed 'from the plaques of demyelination both in the acute and chronic lesions of multiple sclerosis. The oligodendrocytes disappear as abruptly as the myelin sheath.' Friede (1961a), reporting on the enzyme histochemistry of multiple sclerosis, records increased activity of both oxidative enzymes (DPNHtetrazolium reductase and succinic dehydrogenase) and hydrolytic enzymes (acid and alkaline phosphatases), as well as increased neuroglial and mitochondrial populations at the edge of active plaques, but he observed no such increase at the edge of inactive plaques. The increase in neuroglial population at the edge of the active plaque was partly due to oligodendrocytes. Friede agreed with Lumsden that there were no oligodendrocytes in the centre of the plaque.

To increase our scanty knowledge of the pathogenesis of multiple sclerosis it is clearly important to know whether the oligodendroglia are primarily or secondarily affected in the disease and whether or not these cells do in fact disappear from the plaque. For this reason we have analysed the neuroglial population and examined certain histochemical enzyme systems in 33 plaques from 10 cases of multiple sclerosis.

\section{METHODS AND MATERIALS}

The brain and, on one occasion, the cord were obtained at necropsy from 10 cases of multiple sclerosis. With the exception of one case (MS8), the interval between death and examination was less than 24 hours: in all cases the corpse had been stored at $4^{\circ} \mathrm{C}$. in the meanwhile.

Plaques were dissected with a wide surrounding zone of normal tissue so that the diameter of the plaque was not more than half that of the block. In the first three cases (MS1, 2, and 3) unfixed cryostat sections were incubated in enzyme substrates (see below), post-fixed for $2 \mathrm{hr}$. in $15 \%$ formol- $2 \%$ ammonium bromide and were then stained by silver impregnation. The result of the combined histochemical and cytological approach was of very limited value and morphological definition was poor. Likewise, silver impregnation of non-incubated cryostat sections, post-fixed in formol-ammonium bromide, also gave indifferent morphological results. On account of the unsuitability of cryostat sections for silver impregnation, it was decided to use only formol-ammonium-bromidefixed conventionally frozen sections for this purpose and to perform the histochemical reactions on cryostat sections of the adjacent unfixed part of the block. After the first three cases, plaques in subsequent material were usually cut in half. One half was frozen onto a chuck in the Slee chuck-freezer and was then cut unfixed on the Slee cryostat at $6 \mu$. The other half was usually bisected, one part of which was put in $10 \%$ formol-saline, while the other was placed in formol-ammonium bromide. Two bisected plaques were measured before and after fixation in formol-ammonium bromide to assess the amount of shrinkage in the plaque due to fixation. In one case (MS9), only formalin-fixed tissue embedded in paraffin was available for examination.

SILVER IMPREGNATION METHODS After the block had been fixed in formol-ammonium bromide for 12 hours, sections were cut at 15 to $20 \mu$ on the freezing microtome and stained by Hortega's(1956a, republished) silver carbonate method for oligodendrocytes. After further fixation for two to three days at room temperature, sections were again cut from the same block and stained by Hortega's (1954, republished) method for microglia. After still further fixation of the block for about a week at room temperature, sections were once more cut from it and were stained by Cajal's $(1913 ; 1916)$ gold chloride and sublimate method for astroglia.

The following additional staining methods and fixation procedures were used:-

1 Cajal's (1920) modification of Bielschowsky's (1904; 1909) silver impregnation method as adapted for astrocytes.

2 Penfield's (1924; 1930) modifications of Hortega's silver carbonate method for oligodendrocytes.

3 Some blocks were fixed for one and a half to 
six months in either formol-ammonium bromide or $10 \%$ formol-saline. Sections from these blocks were treated for $30 \mathrm{sec}$. to $2 \mathrm{hr}$. with a $50 \%$ aqueous dilution of concentrated ammonium hydroxide $(S G=0.880)$ to reverse the effect of prolonged fixation by formalin and were then stained by Cajal's modification of the Bielschowsky silver method using Weil and Davenport's (1933) silver solution.

4 Sections from blocks fixed for about seven days in $10 \%$ formol saline were stained by Penfield's method (1928) for demonstrating both oligodendrocytes and microglia, by Cajal's method for astrocytes, and by Weil and Davenport's methods (1933) for demonstrating oligodendrocytes and microglia.

5 Part of the block fixed in formalin or formolammonium bromide was sometimes dehydrated, embedded in paraffin, sectioned at $15 \mu$, and stained by haematoxylin and eosin. These preparations were used only to study the nuclear morphology of the neuroglia.

All counts were made with a micrometer square, inserted in the eyepiece, enclosing an area of $0.0144 \mathrm{sq}$. $\mathrm{mm}$. in the field at a magnification of $\times 320$. The counts were made from one 'normal' side of the section, through the plaque, and onwards into the opposite 'normal' side. In some sections two separate counts were made in each field examined. The first count was of neuroglial cells with silver-stained perikaraya, cytoplasmic processes and nuclei; the second count was of total nuclei. Further counts were made on haematoxylin-and-eosin-stained sections of the three different types of neuroglial nuclei and of total neuroglial nuclei.

HISTOCHEMICAL METHODS Cryostat sections from unfixed blocks were stained by adenosine triphosphatase (ATPase) by the methods of Padykula and Herman (1955a and b) and by lactic dehydrogenase and diphosphopyridine nucleotide (DPNH)-tetrazolium reductase (DPN diaphorase). A few sections were also stained for 5-nucleotidase (Wachstein and Meisel, 1957). The dehydrogenase and reductase methods were slight modifications (Adams, Davison, and Gregson, 1963) of the methods of Nachlas, Walker, and Seligman (1958a and b), Hess and Pearse (1961), and Thomas and Pearse (1961); nitroblue tetrazolium (nitro-BT) was used as the electron acceptor. The incubation times were for lactic dehydrogenase one and a half hours, for DPNH-tetrazolium reductase one hour, for ATPase two and a half hours, and for 5-nucleotidase two and a half hours. The sections stained for dehydrogenase and reductase were washed in water to remove substrate and were then briefly rinsed in acetone to remove the diffusible red monoformazan of nitro-BT. All sections were mounted in glycerine jelly.

Formalin-fixed frozen sections, as used for silver impregnation, were stained by Sudan black and by the osmium tetroxide- $\alpha$-naphthylamine (OTAN) method (Adams, 1959) for triglyceride fats, cholesterol esters, and phospholipid. Some sections stained by Sudan black were examined in polarized light in order to distinguish the black orthochroic colour of triglyceride fats and cholesterol esters from the bronze-red dichroic reaction of phospholipid (Diezel, 1957).

\section{RESULTS}

MORPHOLOGICAL RESULTS The criteria used in both silver and haematoxylin and eosin preparations fore the identification of neuroglia by their nuclearo morphology are set out below.

Astrocyte nucleus The nucleus of the astrocyte is the largest among the neuroglia and is usually rounded or slightly oval in shape; it has relatively? sparse chromatin arranged in a vesicular manner.:A nucleolus is often seen but it is not as prominent as in the neurone.

Oligodendrocyte nucleus The nucleus of the oligo-등 dendrocyte is smaller than that of the astrocyte, is $\overline{\bar{c}}$ almost invariably rounded, and has relatively dense chromatin. Usually the chromatin is partly aggregated as a rim inside the nuclear membrane but over ${ }^{\infty}$ the rest of the nucleus it is evenly distributed. There $\vec{O}$ is no distinct nucleolus. The appearance of the nucleus as a whole is smaller and darker than that of the astrocyte.

Microglial nucleus This is the smallest of all the neuroglial nuclei and the most variable in shape: sausage, spindle, angulated, and rounded forms aze characteristically seen. The chromatin is the dense $t \cdot-\overrightarrow{0}$ of all the neuroglial nuclei and is usually evengy distributed over the nucleus. No distinct nucleoligs? is seen.

Neuroglial counts In Table I are set out counts $\underset{\text { eff }}{8}$

TABLE I

NUMBER OF OLIGODENDROGLIA IN 'NORMAL' WHITE 岂 MATTER, EDGE OF PlAQUe, AND PLAQUe

\begin{tabular}{|c|c|c|c|}
\hline $\begin{array}{l}\text { Case and } \\
\text { Plaque Number }\end{array}$ & $\begin{array}{l}\text { 'Normal' Brain } \\
\left.\text { (per } 0.1 \mathrm{~mm} .^{2}\right)\end{array}$ & $\begin{array}{l}\text { Edge } \\
\left(\text { per } 0.1 \mathrm{~mm} .^{2}\right)\end{array}$ & $\begin{array}{l}\text { Plaque } \\
\text { (per } 0.1 \mathrm{~mm} .\end{array}$ \\
\hline MS8c & - & No increase & - \\
\hline MS8e & 121 & 142 & 108 \\
\hline MS1 & 62 & 73 & 21 \\
\hline MS7d (ii) & 119 & 144 & 69 \\
\hline MS7d (i) & 118 & 152 & 76 \\
\hline MS5b & 115 & 151 & 50 \\
\hline MS6b & 133 & 183 & 35 \\
\hline MS10b & 43 & 74 & 61 \\
\hline MS2b (i) & 55 & 100 & 56 \\
\hline MS3c & 63 & 118 & 49 \\
\hline MS2b (ii) & 57 & 115 & 42 \\
\hline MS4c (ii) & 34 & 70 & 10 \\
\hline MS4c (i) & 28 & 76 & 21 \\
\hline
\end{tabular}

oligodendrocytes, stained by Penfield's $(1924 ; 1930)$ methods, in 13 plaques of multiple sclerosis. These $₹$ counts were made through the plaque and through 0 both edges of the plaque into surrounding 'normal' brain. Most plaques show an increase, ranging up to more than twofold, in the oligodendrocyte population at the edge of the lesion. In many plaques a $\mathrm{N}$ large number of surviving oligodendrocytes are seen $N$ at the centre of the lesion (Fig. 1) and in no case did the oligodendrocytes disappear completely. 


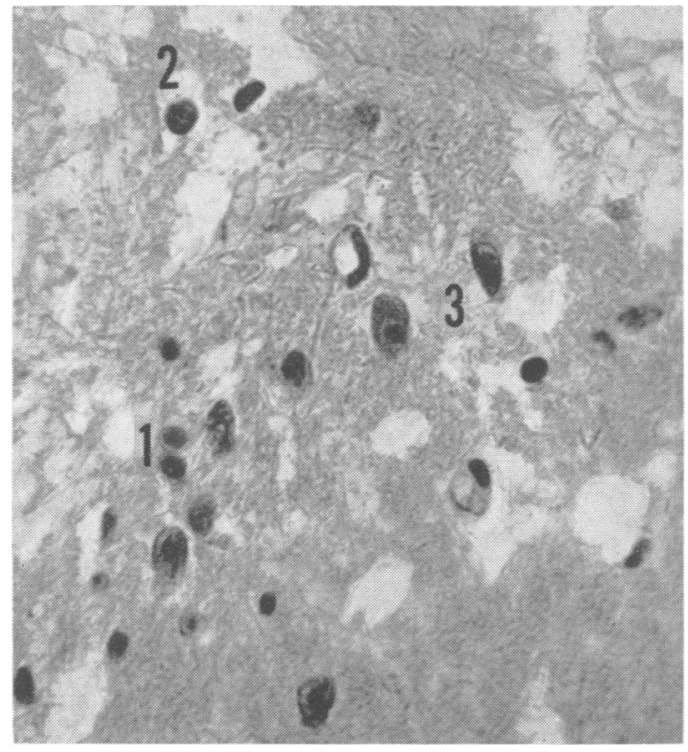

FIG. 1. Oligodendrocytes (1) at centre of old inactive plaque in cord. Some oligodendrocytes are hypertrophied (2) but their nuclear morphology differs from that of astrocytes (3). Haematoxylin and eosin $\times 410$.

In Table II are presented detailed counts of all three neuroglial elements, stained by the respective silver impregnation methods, from five supposedly old plaques of multiple sclerosis. Four of these plaques show an increased neuroglial count, predominantly oligodendrocytes, at their edges but the fifth shows no such increase. In Table III detailed counts are shown for three small plaques where there

\section{TABLE II}

DIFFERENTIAL NEUROGLIAL COUNTS IN FIVE LARGE PLAQUES

\begin{tabular}{|c|c|c|c|c|}
\hline $\begin{array}{l}\text { Case and } \\
\text { Plaque } \\
\text { Number }\end{array}$ & Zone & $\begin{array}{l}\text { Oligodendro- } \\
\text { cytes }(\text { cells } \\
\left.\text { per } 0.1 \mathrm{~mm} .^{2}\right)\end{array}$ & $\begin{array}{l}\text { Astrocytes } \\
(\text { cells per } \\
\left.0.1 \mathrm{~mm} .^{2}\right)\end{array}$ & $\begin{array}{l}\text { Microglia } \\
\text { (cells per } \\
\left.0 \cdot 1 \mathrm{~mm} .^{2}\right)\end{array}$ \\
\hline $4 c$ (iii) & $\begin{array}{l}\text { Normal } \\
\text { Edge } \\
\text { Centre }\end{array}$ & $\begin{array}{r}112 \\
139 \\
31\end{array}$ & $\begin{array}{l}15 \\
21 \\
22\end{array}$ & $\begin{array}{l}20 \\
35 \\
11\end{array}$ \\
\hline $4 d$ & $\begin{array}{l}\text { Normal } \\
\text { Edge } \\
\text { Centre }\end{array}$ & $\begin{array}{r}75 \\
126 \\
56\end{array}$ & $\begin{array}{l}11 \\
18 \\
39\end{array}$ & $\begin{array}{r}17 \\
21 \\
4\end{array}$ \\
\hline $6 \mathrm{~b}$ & $\begin{array}{l}\text { Normal } \\
\text { Edge } \\
\text { Centre }\end{array}$ & $\begin{array}{r}133 \\
183 \\
35\end{array}$ & $\begin{array}{r}8 \\
17 \\
15\end{array}$ & $\begin{array}{l}28 \\
36 \\
12\end{array}$ \\
\hline 7d (i) & $\begin{array}{l}\text { Normal } \\
\text { Edge } \\
\text { Centre }\end{array}$ & $\begin{array}{r}118 \\
152 \\
76\end{array}$ & $\begin{array}{l}21 \\
28 \\
31\end{array}$ & $\begin{array}{l}29 \\
35 \\
13\end{array}$ \\
\hline $7 \mathrm{~d}$ (iii) & $\begin{array}{l}\text { Normal } \\
\text { Edge } \\
\text { Centre }\end{array}$ & $\begin{array}{r}128 \\
125 \\
51\end{array}$ & $\begin{array}{l}24 \\
32 \\
24\end{array}$ & $\begin{array}{l}39 \\
33 \\
36\end{array}$ \\
\hline
\end{tabular}

TABLE III

DIFFERENTIAL NEUROGLIAL COUNTS IN THREE SMALL PLAQUES

\begin{tabular}{|c|c|c|c|c|}
\hline $\begin{array}{l}\text { Case and } \\
\text { Plaque } \\
\text { Number }\end{array}$ & Zone & $\begin{array}{l}\text { Oligodendro- } \\
\text { cytes (cells } \\
\left.\text { per } 0.1 \mathrm{~mm} .^{2}\right)\end{array}$ & $\begin{array}{l}\text { Astrocytes } \\
\text { (cells per } \\
\left.0.1 \mathrm{~mm}^{2}\right)\end{array}$ & $\begin{array}{l}\text { Microglia } \\
\text { (cells per } \\
0.1 \mathrm{~mm} .^{2} \text { ) }\end{array}$ \\
\hline MS9 & $\begin{array}{l}\text { Normal } \\
\text { Edge } \\
\text { Centre }\end{array}$ & $\begin{array}{l}100 \\
364 \\
151\end{array}$ & $\begin{array}{l}20 \\
28 \\
23\end{array}$ & $\begin{array}{r}32 \\
128 \\
94\end{array}$ \\
\hline MS8e & $\begin{array}{l}\text { Normal } \\
\text { Edge } \\
\text { Centre }\end{array}$ & $\begin{array}{l}121 \\
142 \\
108\end{array}$ & $\begin{array}{l}18 \\
18 \\
21\end{array}$ & $\begin{array}{l}39 \\
77 \\
55\end{array}$ \\
\hline MS10b & $\begin{array}{l}\text { Normal } \\
\text { Edge } \\
\text { Centre }\end{array}$ & $\begin{array}{l}43 \\
74 \\
61\end{array}$ & $\begin{array}{l}9 \\
9 \\
7\end{array}$ & $\begin{array}{l}13 \\
25 \\
22\end{array}$ \\
\hline
\end{tabular}

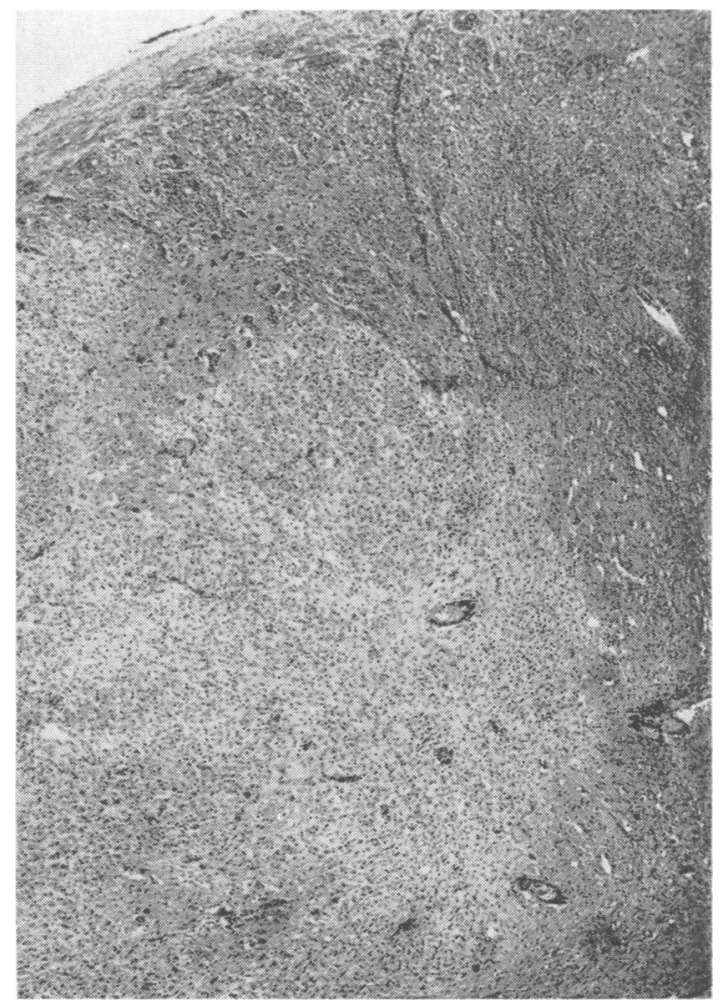

FIG. 2. Small early plaque in brain with increased neuroglial density and myelin pallor throughout the lesion. Haematoxylin and eosin $\times 33$.

is an increased neuroglial count, mainly of oligodendrocytes and microglia, throughout the lesion (Fig. 2). For reasons presented later these small plaques are regarded as relatively early lesions.

In Figs. 3 and 4 histograms show the counts of total neuroglial nuclei compared with the sum of the differential counts for each separate neuroglial 

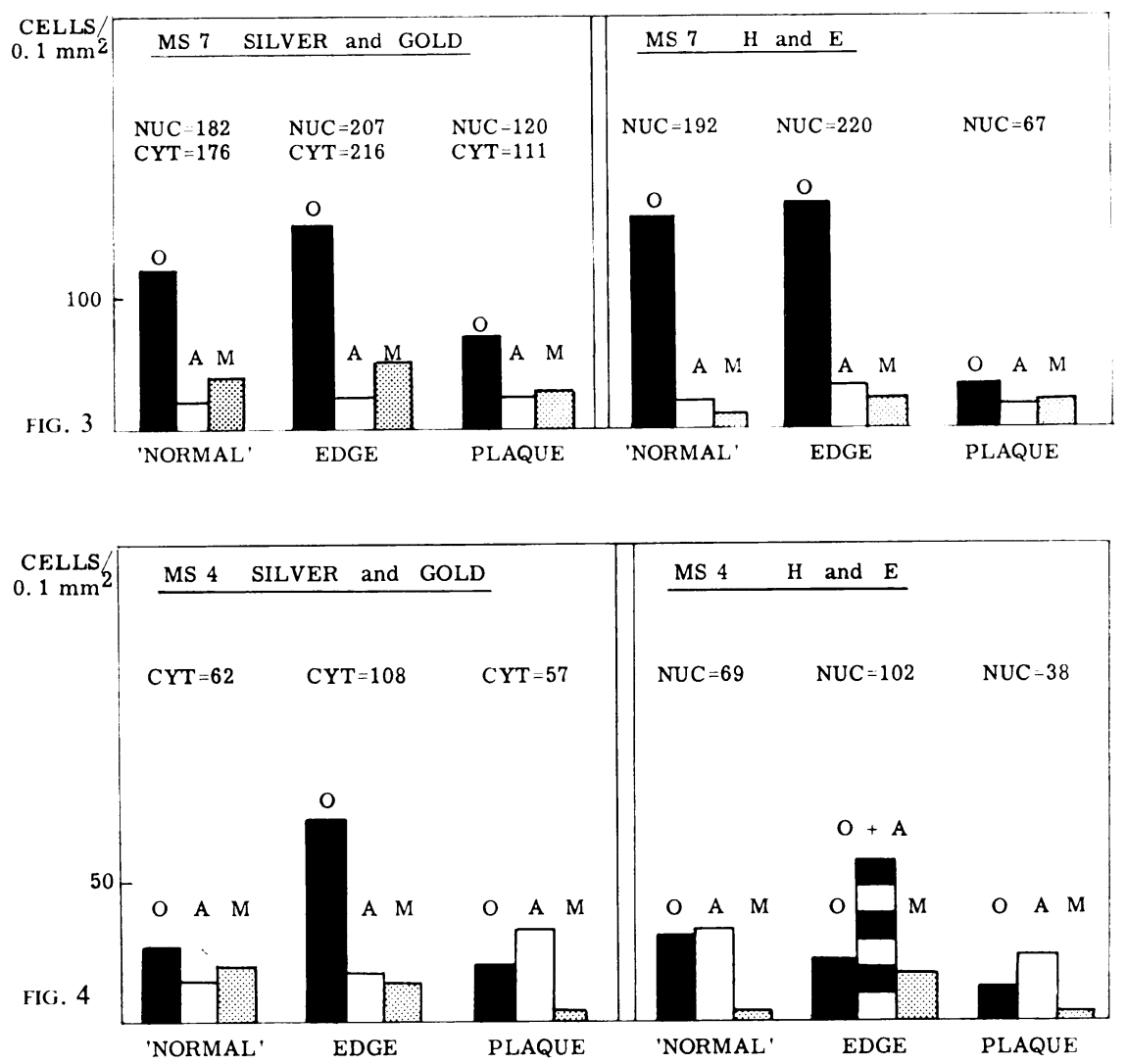

FIG. 3. Differential neuroglial counts obtained in the edge and centre of an inactive older plaque (MS7) and in surrounding brain (a) by silver or gold impregnation; (b) by haematoxylin and eosin. NUC = total neuroglia obtained by nuclear count. $C Y T=$ total neuroglia obtained by sum of counts for specific cytoplasmic impregnation by silver or gold. $O=$ oligodendroglia, $A=$ astroglia, $M=$ microglia.

FIG. 4. Differential neuroglial counts (as for Fig. 3) in active older plaque (MS4). Abbreviations are as for Fig. 3. $O+A=$ hypertrophied oligodendrocytes plus astrocytes; cells in this category could not be clearly differentiated by their nuclear morphology.

type; it can be seen that there is good correspondence between the total neuroglial count obtained by either method.

Cytological changes in the neuroglia The detailed cytological changes in the neuroglia around and in the plaque are best illustrated by a typical lesion such as in any of the first four cases of Table II. An increase in microglia is seen as far out as $5 \mathrm{~mm}$. from the edge of the plaque. These cells show all the usual characteristics of activation (Fig. 5), such as cytoplasmic hypertrophy, thickening of the spiny processes, vesiculation of the chromatin, and rounding of the usually elongated nucleus. Lipid-laden microglia (gitter cells) can usually be distinguished only at the edge of the plaque and just inside it.
The astrocytes show a slight numerical increase at the edge and centre of the plaque. Those at the edge of the plaque show all the usual features of reactivity (Fig. 6) such as hypertrophy and deeper staining of the perikaryon and processes; the nucleus may enlarge and some cells are binucleate or even multinucleate. Inside some plaques astrocytes may be quite prominent and, in this site, they are often arranged isomorphically. In the centre of other plaques, presumably of greater age, gliosis is so marked that the perikaryon and nucleus of the astrocyte have often disappeared.

The population of oligodendrocytes is usually, but not always, increased at the edge of the plaque (Fig. 7) and this increase is greater than that of the 


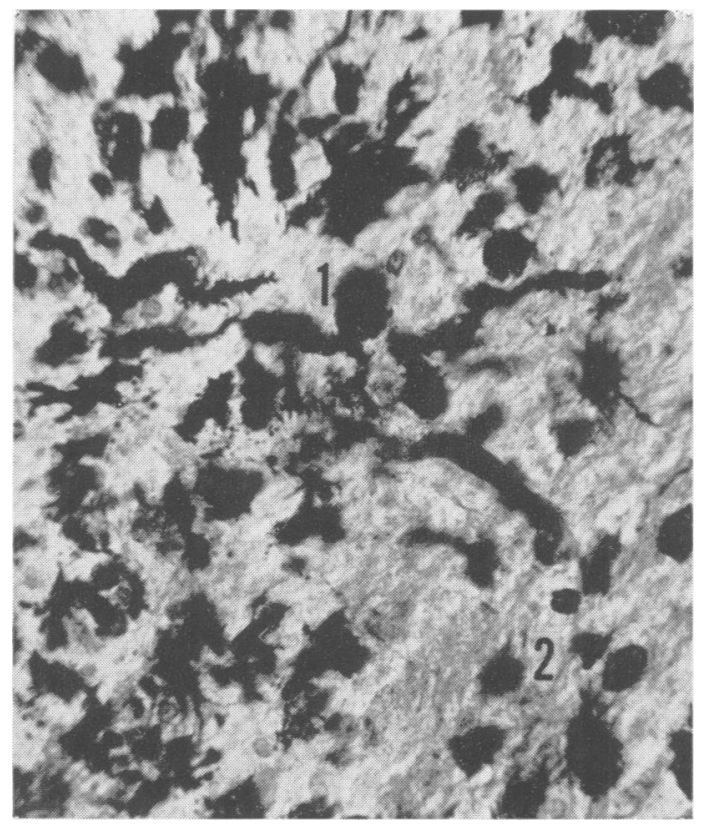

FIG. 5. Edge of active older plaque showing numerous activated microglia. including gitter cells (1). Numerous oligodendrocyte nuclei are also seen (2). Modified Weil and Davenport silver method, $\times 350$.

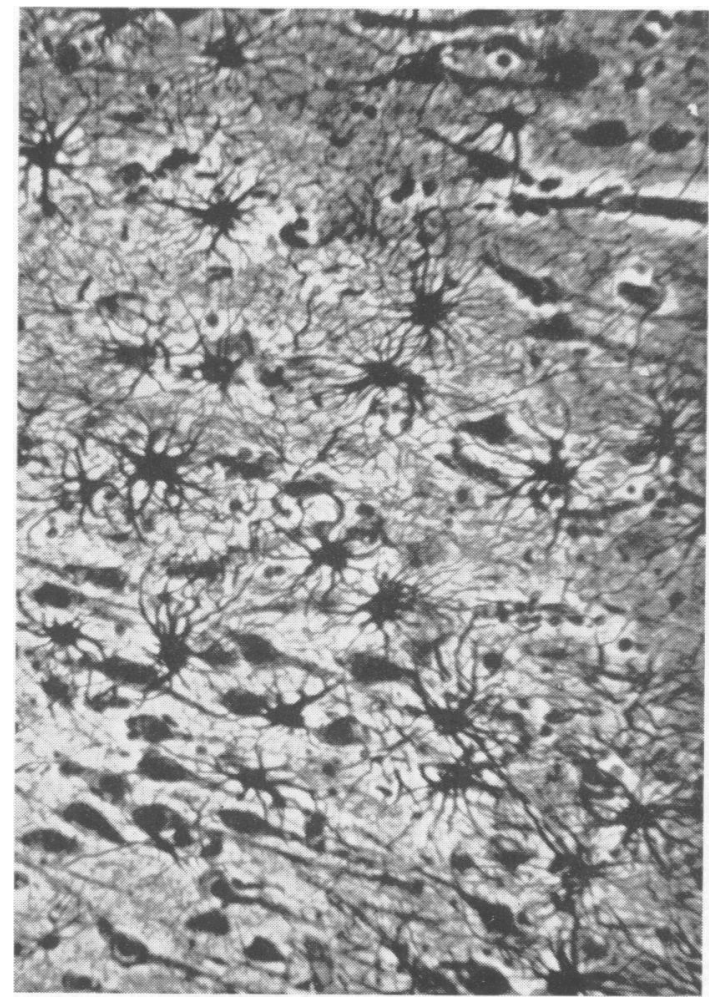

FIG. 6. Active older plaque with reactive fibrous astrocytes at its edge. Cajal-Bielschowsky silver method, $\times 200$.

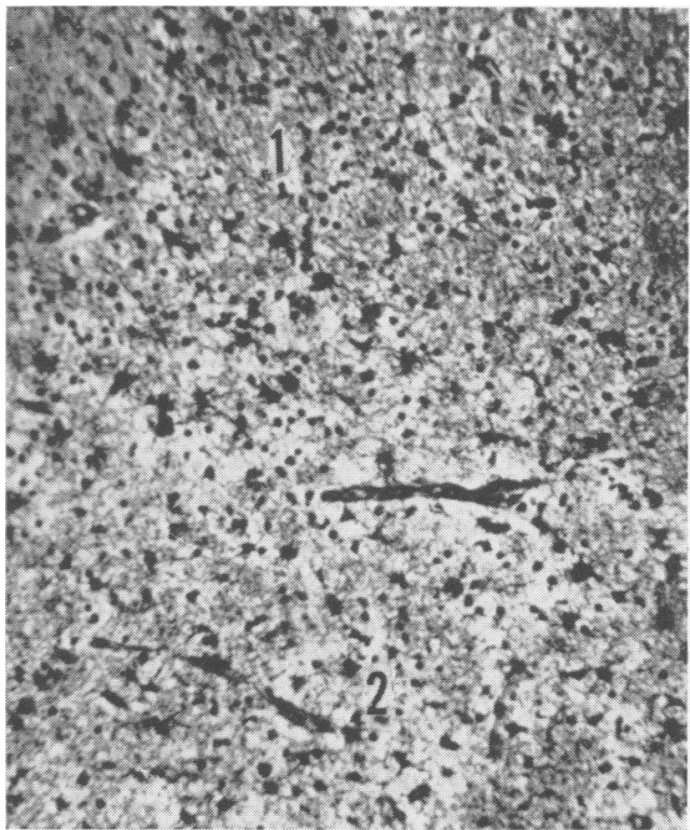

FIG. 7. Small plaque with increased neuroglial density at edge of lesion (1). The large cells at the edge are reactive astrocytes, while the cells with small round nuclei are mainly oligodendrocytes. Note survival of oligodendrocytes in the centre of the plaque (2). Penfield's silver carbonate method, $\times 200$.

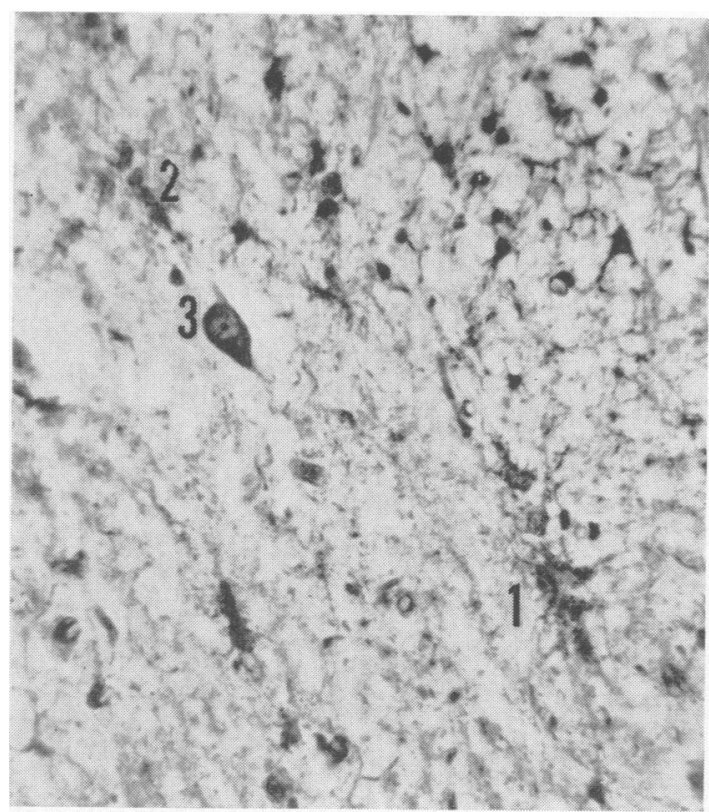

FIG. 8. Active older plaque showing a row of hypertrophied oligodendrocytes just inside edge (1). Compare with a row of normal interfascicular oligodendrocytes (2) next to a neurone (3) outside edge of plaque. Hortega's silver carbonate method, $\times 350$. 


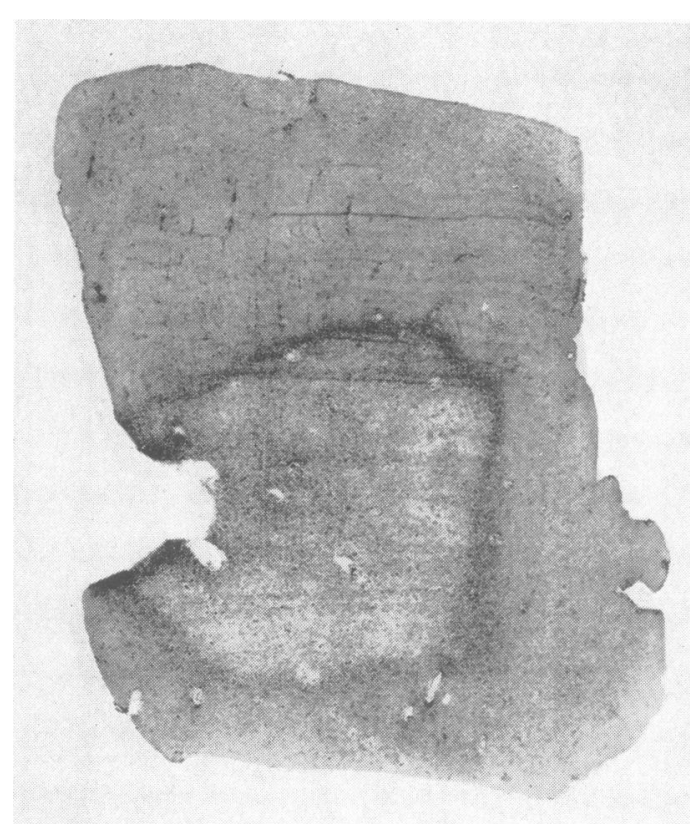

FIG. 9. Lactic dehydrogenase activity at the edge of an active older plaque of multiple sclerosis, $\times 5$.

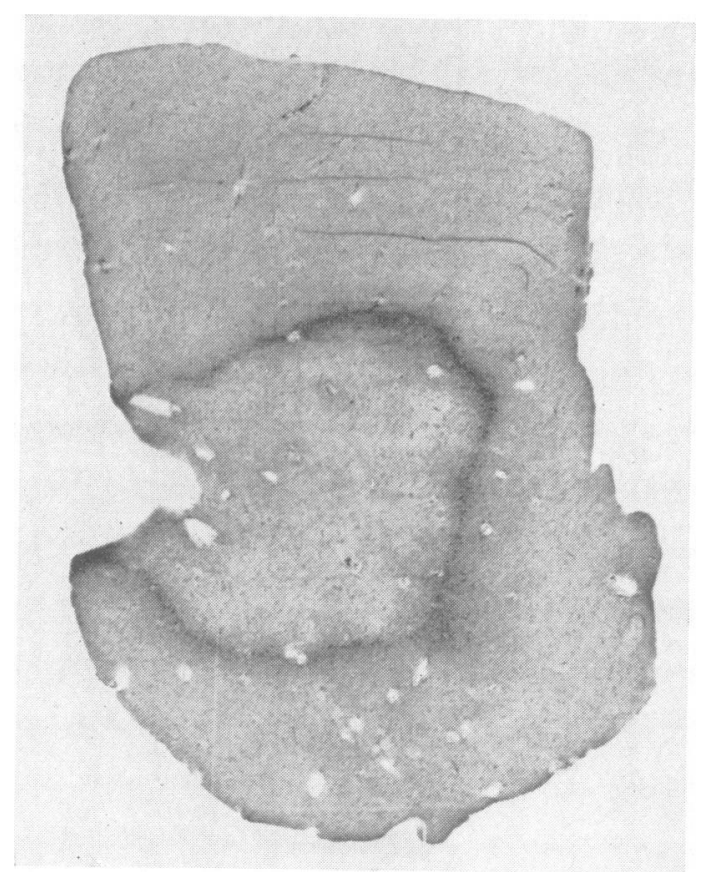

FIG. 10. Same as Fig. 9 for ATPase, $\times 5$. other neuroglia. In silver-impregnated sections some oligodendrocytes appear cytologically normal but others, which we regard as hypertrophied oligodendrocytes, show enlargement of the perikaryon, processes, and, sometimes, the nucleus (Fig. 8). In haematoxylin and eosin sections the nucleus of the latter type of oligodendrocyte is more the size of that of the astrocyte (see Fig. 4) and its chromatin is less dense than that of the normal oligodendrocyte. As already stated, a large number of surviving oligodendrocytes are usually present in the centre of the plaque. Many of these surviving oligodendrocytes are either cytologically normal or hypertrophied but some show nuclear pyknosis and distortion, cytoplasmic atrophy, and other signs of degeneration.

Shrinkage measurements Measurement of the maximum and minimum diameters of the two plaques showed shrinkage of 19 and $28 \%$ in the surface area as a result of fixation in formolammonium bromide. Any comparable shrinkage in the surrounding normal brain could not be accurately measured.

HISTOCHEMICAL RESULTS At the edge of most of the plaques examined (Figs. 9 and 10) there is an increase of all the enzymes studied (lactic dehydrogenase, DPNH-tetrazolium reductase, and ATPase). Some plaques, however, show little enzyme activity and it is apparent that the amount of enzyme activity at the edge of the plaque is proportional to the increase in oligodendrocytes in this zone (Table IV).

In normal brain surrounding the plaque moderate?

\section{TABLE IV}

CORRELATON BETWEEN INCREASE OF OLIGODENDROGLIA AND INCREASED ENZYME ACTIVITY AT EDGE OF PLAQUE

\begin{tabular}{lcc}
$\begin{array}{l}\text { Case and Plaque } \\
\text { Number }\end{array}$ & $\begin{array}{c}\text { \% Increase in } \\
\text { Oligodendroglia }\end{array}$ & $\begin{array}{l}\text { Increase in Enzyme } \\
\text { Activity }\end{array}$ \\
\hline MS8c & $\simeq 0$ & + \\
MS8e & +17 & + \\
MS1 & +18 & + \\
MS7d (ii) & +21 & + \\
MS7d (i) & +28 & + \\
MS5b & +31 & ++ \\
MS6b & +37 & ++ \\
MS10b & +72 & + \\
MS2b (i) & +82 & ++ \\
MS3c & +87 & +++ \\
MS 2b (ii) & +102 & +++ \\
MS4c (ii) & +106 & +++ \\
MS4c(i) & +171 & +
\end{tabular}

enzyme activity is seen in oligodendrocytes and slight activity is present in mitochondria scattered through the neuropil (Fig. 11). Astrocytes and microglia cannot be identified in enzyme preparations of normal areas of white matter or grey matter. In the edge of the plaque most of the increased enzyme 


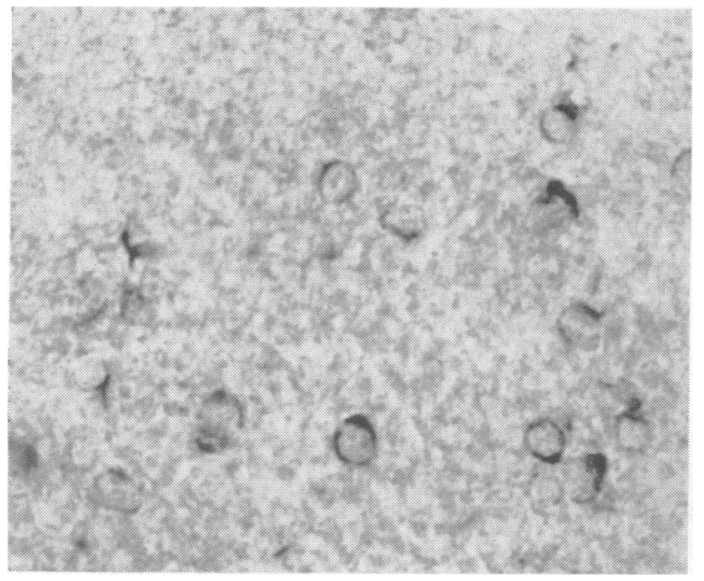

FIG. 11. Lactic dehydrogenase activity in the form of perinuclear crescents and haloes in oligodendrocytes and in the mitochondria of the neuropil in normal white matter, $\times 550$.

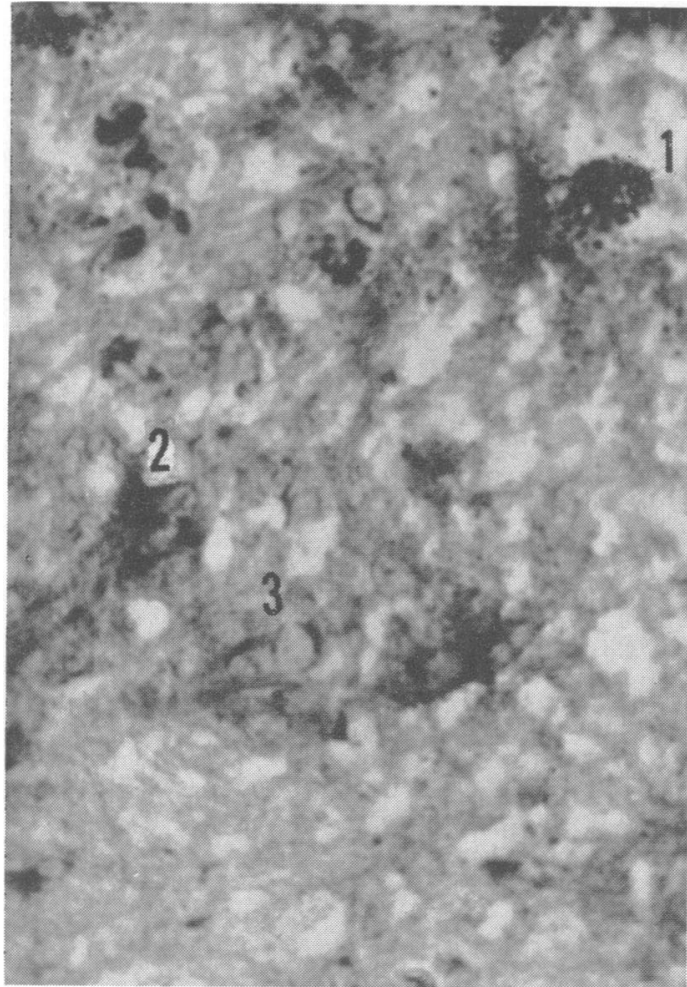

FIG. 12. Strong lactic dehydrogenase activity in mitochondria of the neuropil at the edge of the active older plaque of Fig. 9. Note strong reactions in activated microglia (1), reactive astrocytes (2), and oligodendrocytes (3), $\times 550$. activity appears to be in the form of a fine granular, probably mitochondrial, reaction scattered diffusely in the neuropil (Fig. 12) but part of this activity is localized in the numerically scanty reactive astrocytes, in activated microglia, and in the numerous oligodendrocytes at the periphery of the lesion. Intense reactions for lactic dehydrogenase and DPNH-tetrazolium reductase are seen in the perikaryon of the reactive astrocyte; less intense,

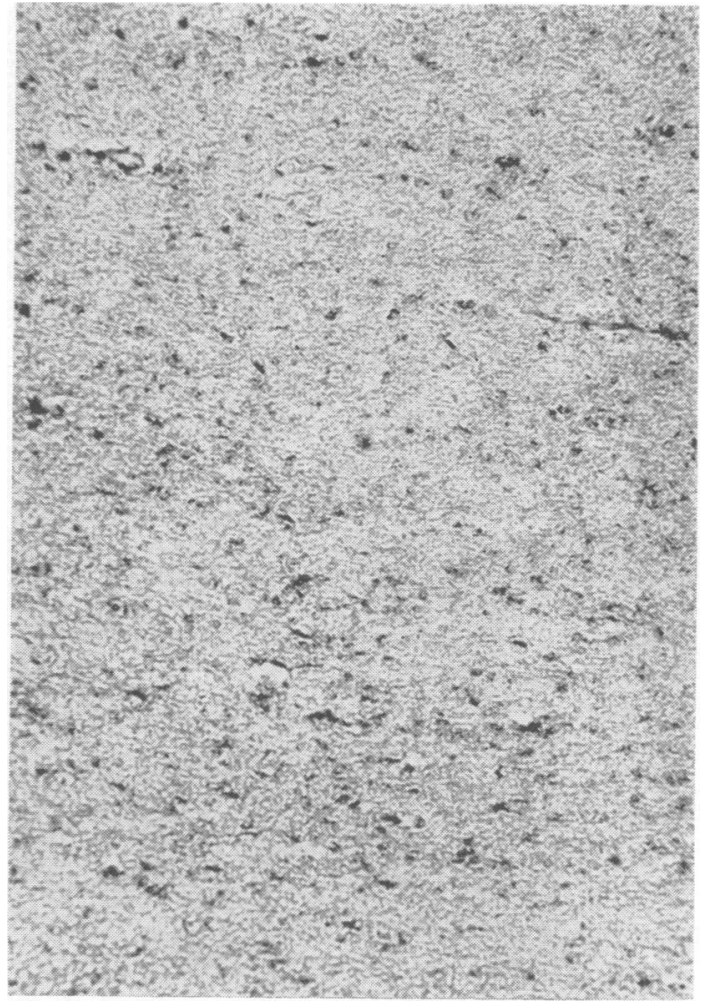

FIG. 13. Increased lactic dehydrogenase activity and increased neuroglial population throughout a small early plaque (bottom). Compare with surrounding normal brain (top), $\times 95$.

coarsely granular reactions appear in the perikaryon of the activated microglial cell; and moderately intense reactions in the form of complete or partial perinuclear haloes are seen in the active oligodendrocyte (Fig. 12). No reaction can be identified in axons in or around the plaque.

Of the three small plaques, where an increased neuroglial count was obtained throughout the lesion (Table III), two plaques were available for enzyme studies (MS8b, MS10b). Both plaques show increased 


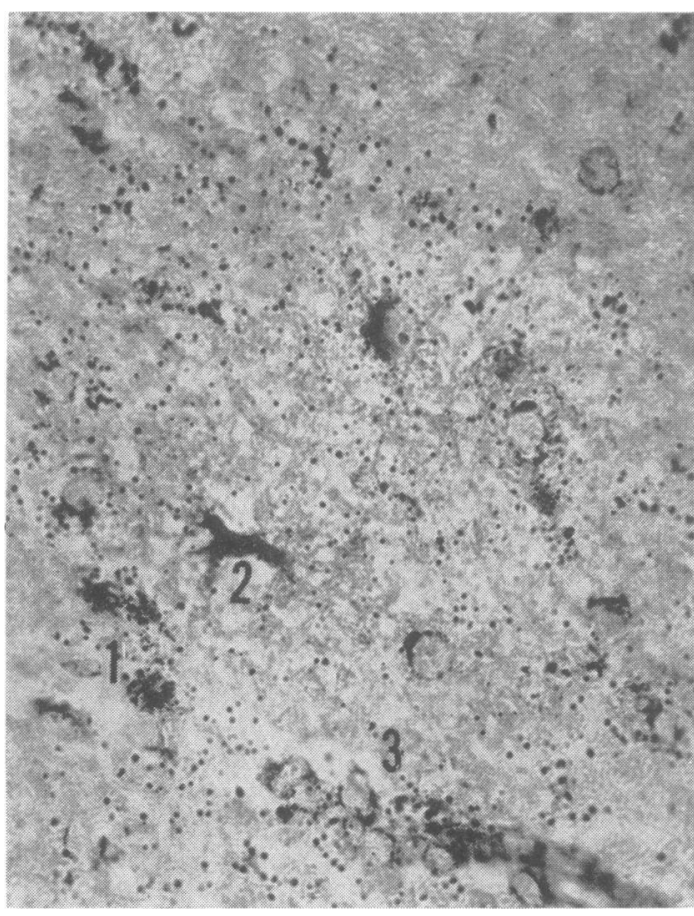

FIG. 14. Diffuse mitochondrial and coarsely granular reaction for lactic dehydrogenase in small early plaque. Note strong reactions in activated microglia (1), reactive astrocytes (2), and oligodendrocytes (3), $\times 550$.

enzyme activity over the whole lesion (Fig. 13) but the activity is substantially less than that seen at the edge of larger plaques and, moreover, the edges of these small plaques do not stand out as enzymatically active zones. The increased enzyme activity within the small plaque is mainly in the form of the diffuse mitochondrial reaction referred to above but enzyme activity localized in the perikaryon of reactive astrocytes, activated microglia, and oligodendrocytes contributes to the total reaction (Fig. 14).

The lipid stains, Sudan black and OTAN, show breakdown products of myelin within the microglia, usually at the edge of the plaque. The extent of these lipid accumulations does not appear to be related to the size or enzyme activity of the plaque. No residual myelin sheaths are seen within any of the plaques examined but, at the edge of many lesions, partly preserved sheaths are of common occurrence.

\section{DISCUSSION}

The available clinical bistories of our 10 cases of multiple sclerosis did not allow any reasonable conclusions to be made about the age of any of the plaques examined. For this reason certain criteria are advanced to distinguish between early and old $\frac{\text { o }}{Z}$ plaques. An 'early' plaque is regarded as one that is relatively small and contains large numbers of microglia and oligodendrocytes throughout the lesion; reactive astrocytes are present but the normalo astrocyte is inconspicuous. The 'older' plaque is usually but not always bigger, contains relatively few microglia, and astrocytes or gliosis are prominent in the centre of the lesion. Increased neuroglia at the edge of the lesion has been taken as evidence of $\Rightarrow$ activity in these older plaques.

These postulates are consistent with currento neuropathological opinion, but they can only be을 taken as tentative and approximate indications of $\frac{\bar{c}}{\frac{5}{5}}$ plaque age and activity (see Friede, 1961a). All the $\stackrel{\mathbb{Q}}{\Omega}$ plaques examined contained some lipid breakdown products but the presence of these lipids was of no value to us in assessing their age.

CYTOLOGY OF NEURoglia IN THE PLAQUe The major element in the increase of neuroglia at the edge of the active plaque was found to be the oligodendrocyte. In the small early plaque, as defined above, the increase in oligodendrocytes is throughotit the lesion but in the active older plaque the increase $\vec{O}$ is mainly at the edge. At the centre of the latter type of plaque there is a reduction in the number of $\triangle$ oligodendrocytes but this loss is far from complete. These observations accord neither with those $8 \mathrm{fo}$

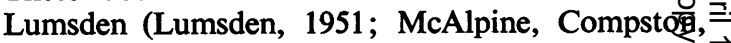
and Lumsden, 1955), who regarded the disappearanseco of the oligodendrocyte as an essential histologicalt and pathogenic feature of the plaque in multiple sclerosis, nor with those of Friede (1961a) who re-文 corded the absence of oligodendrocytes from the centre of both active and quiescent plaques.

Shrinkage of the plaque during fixation cannotक्ष account for the observed increase in oligodendrocyte $\stackrel{2}{\Rightarrow}$ population. Even in the unlikely event that the sur-을 rounding normal brain did not shrink after fixation and that shrinkage was confined to the plaque, the contraction in the area of the latter was not more than $28 \%$. This slight contraction could not, therefore, account for the maximum increase of $171 \%$ in the oligodendrocyte count at the edge of the plaque.

It could be argued that our identification of the different types of neuroglia by silver impregnation of their cytoplasm was unreliable and that oligodendrocytes were not properly distinguished from other neuroglial cells. To meet this argument, it was shown that the sum of the individual counts of specifically silver-stained oligodendrocytes, astrocytes, and microglia was approximately equal to the total neuroglial nuclear count. This shows that the three different types of neuroglia were accuratelyw classified. If the silver impregnation methods hade 
been unreliable, the same cell type would have been counted in two or all three categories and the sum of these 'silver' counts would, accordingly, have been significantly higher than the total nuclear count.

Good correlation was also obtained in normal brain between 'silver' counts of oligodendrocytes and counts on haematoxylin and eosin sections of cells with the nuclear morphology of oligodendrocytes. In the edge and centre of the plaque, however, some cells stained by silver as oligodendrocytes appeared by their nuclear size and morphology in haematoxylin and eosin sections to be intermediate between oligodendrocyte and astrocyte. We have regarded such cells as hypertrophied oligodendrocytes but an acceptable alternative is that they are intermediate cells (Penfield and Cone, 1926) or are in process of metamorphosis from oligodendrocyte to astrocyte (Smart and Leblond, 1961).

ENZYME HISTOCHEMISTRY OF THE PLAQUE The marked increase in activity of oxidative and hydrolytic enzymes at the edge of the active older plaque coincides with increased oligodendrocyte population in this zone. In the old, inactive plaque, astrocytes or their processes were prominent throughout the lesion but enzyme activity and the oligodendrocyte count were low. In the supposedly early plaque both enzyme activity and oligodendrocyte population were increased throughout the lesion but astrocytes were relatively inconspicuous. These three observations strongly suggest that the increase in enzyme activity is related to the increase in oligodendroglia.

Although some enzyme activity is located in the perikaryon of oligodendrocytes, reactive astrocytes, and activated microglia, the major part of the enzyme reaction in or around the plaque is in the form of fine granules, possibly mitochondrial, in the neuropil. This granular activity is much greater than that seen in normal white matter (Wolfgram and Rose, 1959; Friede, 1961b; Adams, 1962; Adams, Davison, and Gregson, 1963); it differs from the enzyme distribution described or illustrated in axons, capillaries, reactive astrocytes, and activated microglia (Rubinstein, Klatzo, and Miquel, 1962; Smith and Rubinstein, 1962; Friede, 1962; Osterberg and Wattenberg, 1962).

We conclude, therefore, that the increased enzyme activity at the edge of the plaque is mainly located in neuroglial mitochondria scattered diffusely through the neuropil. Since the increase in oligodendrocytes is greater in absolute numbers than that of the other neuroglia, we tentatively suggest that the enzymatically active mitochondria at the edge of the plaque are predominantly oligodendroglial.

The observed increase in both oligodendroglial population and enzyme activity at the edge of the plaque raises several questions. The first problem is whether the numerical increase in oligodendrocytes is due to their proliferation or merely to their infiltration from other parts of the brain. Available evidence suggests that oligodendrocytes can in fact undergo cell division (Hortega, 1956b, republished; Lewis and Swank, 1953; Smart and Leblond, 1961; Adrian and Walker, 1962). The main problem raised by these observations is, however, whether this increased oligodendroglial activity precedes the formation of plaques or whether it is merely a resorptive or reparative response to demyelination comparable to cellular proliferation in Wallerian degeneration (Abercrombie and Johnson, 1946; Cavanagh and Webster, 1955). It is hoped that study of experimental demyelinating lesions may help to clarify the latter problem.

\section{SUMMARY}

Silver impregnation methods for neuroglia and histochemical methods for enzymes were used in a histological examination of 33 plaques from 10 cases of multiple sclerosis. An increase in neuroglial count (predominantly oligodendrocytes) and increased oxidative enzyme and ATPase activities are found at the edge of supposedly active plaques. Inactive plaques show no such increase in neuroglial or enzyme activity but some surviving oligodendrocytes are seen even in the centre of relatively old plaques. Some small plaques, which were considered early lesions, show an increased neuroglial count, mainly oligodendrocytes and microglia, throughout the lesion; enzyme activity is moderately increased in these plaques. The increase in oxidative enzyme activity, whether at the edge or centre of the plaque, is mainly in diffuse mitochondrial form but enzyme activity in the perikaryon of oligodendrocytes, reactive astrocytes, and activated microglia contributes towards the total reaction. As the oligodendrocyte is the predominant cell in active lesions, it was tentatively suggested that the enzymatically active mitochondria are oligodendroglial. The main problem raised by these observations is whether the increases in oligodendroglial population and enzyme activity precede formation of plaques or whether they are merely a response to a focus of demyelination.

We wish to express our thanks to the pathologists who made this material available to us through the offices of the Department of Chemical Pathology (Professor R. H. S. Thompson), Guy's Hospital Medical School.

We acknowledge suggestions made by Dr. J. B. Cavanagh and Professor G. Payling Wright and the assistance of Mrs. O. B. High. 


\section{REFERENCES}

Abercrombie, M., and Johnson, M. L. (1946). J. Anat. (Lond.), 80, 37. Adams, C. W. M. (1959). J. Path. Bact., 77, 648.

- (1962). Develop. Med. Child Neurol., 4, 393.

_- Davison, A. N., and Gregson, N. A. (1963). J. Neurochem. in press.

Adrian, E. K., and Walker, B. E. (1962). J. Neuropath. exp. Neurol., 21, 597.

Barrnett, R. J., and Seligman, A.M. (1958b). J. biophys. biochem. Cytol., 4, 169

Bielschowsky, M. (1904). J. Psychol. Neurol. (Lpz.), 3, 169.

(1909). Ibid., 12, 135.

Cajal, S. Ramon y. (1913). Trab. Lab. Invest. biol. (Madr.), 11, 219. (1916). Ibid., 14, 155 .

_ (1920). Cited by Gatenby, J. B., and Painter, T. S. (1937). In The Microtomist's Vade-Mecum, 10th ed., p. 550. Churchill, London.

Cavanagh, J. B., and Webster, G. R. (1955). Quart. J. exp. Physiol., $40,12$.

Dawson, J. W. (1916). Trans, roy. Soc. Edinb., 50, 517.

Diezel, P. B. (1957). Die Stoffwechselstörungen der Sphingolipoide, p. 38. Springer-Verlag, Berlin.

Friede, R. L. (1961a). Arch. Neurol. (Chic.), 5, 433.

(1961b). J. Neurochem., 8, 17.

- (1962). J. Neuropath. exp. Neurol., 21, 471.

Hess, R., and Pearse, A. G. E. (1961). Exp. Cell. Res., 25, 187.

Hortega, P. Del Rio (1954). Arch. Histol. (B. Aires), 5, 105. (Republished.) (1956a). Ibid., 6, 132. (Republished.)

(1956b). Ibid., 6, 239. (Republished.)

Lewis, R. C., and Swank, R. L. (1953). J. Neuropath. exp. Neurol., 12 57.

Lumsden, C. E. (1951). Brit. med. J., 1, 1035.

McAlpine, D., Compston, N. D., and Lumsden, C. E. (1955). Multiple Sclerosis. Livingstone, Edinburgh.

Nachlas, M. M., Walker, D. G., and Seligman, A. M. (1958a). J. biophys. biochem. Cytol., 4, 29.

Osterberg, K. A., and Wattenberg, L. W. (1962). Arch. Neurol. (Chic.), $7,211$.

Padykula, H. A., and Herman, E. (1955a). J. Histochem. Cytochem. 3,161 .

(1955b). Ibid., 3, 170 .

Penfield, W. (1924). Brain, 47, 430

(1928). Amer. J. Path., 4, 153.

(1930). Ibid., 6, 445

, and Cone, W. (1926). Arch. Neurol. Psychiat. (Chic.), 16, 131

Rubinstein, L. J., Klatzo, I., and Miquel, J. (1962). J. Neuropath., 21, 116.

Smart, I., and Leblond, C. P. (1961). J. comp. Neurol., 116, 349.

Smith, B., and Rubinstein, L. J. (1962). J. Path. Bact., 83, 572.

Thomas, E., and Pearse, A. G. E. (1961).Z. Zellforsch. Abt. Histochem., 2, 266.

Wachstein, M., and Meisel, E. (1957). Amer. J. clin. Path., 27, 13.

Weil, A., and Davenport, H. A. (1933). Arch. Neurol. Psychiat. (Chic.), 30, 175

Wolfgram, F., and Rose, A. S. (1959). Exp. Cell Res., 17, 526. 